\title{
3-D process modelling of ancient storm-dominated deposits by an event-based approach
}

\author{
L. Laigle ${ }^{1}$, P. Joseph ${ }^{1}$, G. de Marsily ${ }^{2} \&$ S. Violette ${ }^{2}$ \\ ${ }^{1}$ Institut Français du Pétrole, France \\ ${ }^{2}$ Université Pierre \& Marie Curie, France and CNRS, France
}

\begin{abstract}
The characterization of porosity and permeability heterogeneities in sedimentary rocks is of primary importance for the understanding of fluid flows. These heterogeneities are directly linked to the nature and geometry of the sediment deposits which were created during a time span ranging from tens to hundreds of thousands of years. An ability to model numerically the physical processes that explain the present-day distribution and architecture of reservoir rocks is a major advantage. A numerical model was developed to simulate erosion, transport and deposition of sediments along marine clastic coasts, from the foreshore to the offshore environment. It is based on the assumption that the preserved heterogeneities are mainly the result of the succession of fair-weather periods and exceptional events (storms and/or fluvial floods). This model is designed for 3-D characterisation of deposits generated by storms. The transport module accounts for the impact of two unidirectional currents: 1/ a strong return current originated by the coastal surge due to water pushed by the wind and 2 / a littoral drift current caused by an energy transfer during wave surfing near the shore. These currents interact at the sea bottom with wave-induced oscillatory currents and are responsible for sea floor erosion and particle matter mobilisation. Between storm events, fair-weather deposits are modelled through an average deposition process. After a synthetic case, the storm modelling module is calibrated to a present-day environment in the Gulf of Lions (France). By allowing us to focus on heterogeneity distribution, this innovative approach gives promising prospects to help in assigning to geological models realistic petrophysical properties.
\end{abstract}

Keywords: coastal environment, event-and-process-based modelling, downwelling, littoral current, sediment transport, heterogeneities, reservoir, Gulf of Lions. 


\section{Introduction}

Geological reservoirs are of economic importance since they may contain raw fluids (water, hydrocarbons), or be used for $\mathrm{CO} 2$ storage. Made of porous and permeable sedimentary deposits, their constitutive rocks have been formed during a long period of time, ranging from tens to hundreds of thousands of years. The numerical simulation of fluid flow inside reservoirs has been attracting increasing attention for many years. It requires that petrophysical properties be assigned to the spatially discretized geological model, i.e. porosity and permeability values in each mesh. Heterogeneities of these properties have a major impact on the fluid flow direction and are directly linked to the nature and geometry of the sediment deposits. We present a new 3-D numerical model whose aim is to simulate deterministically the facies distribution in clasticdominated coastal environments. The approach, physical concepts and first results are detailed below.

\section{General approach of the numerical model}

\subsection{Direct modelling of sedimentary processes...}

Commonly subsurface fluid flow simulations are performed on 3-D grids constructed from a geological model to which facies properties such as porosity and permeability have been assigned. The methods used to inform these grids can be divided into two categories, probabilistic and genetic. The direct information available on the physical properties is generally deduced from sparse raw data, such as cores and well measurements. While the probabilistic approach is able to respect the well data with a weak to medium constraint on the properties between control points, the genetic approach has the great advantage of providing a more physically based representation of the nature and spatial distribution of these heterogeneities, although the calibration may remain a problem. The latter approach was explored here through the modelling of processes that actively participate in erosion, transport and deposition of sediments within a time-frame representative of the deposition of reservoir sedimentary bodies.

\section{2 ... only during exceptional events}

As of today, the relationship between time and sedimentary recording is not well established and the scientific community is currently still discussing this issue. Two contradictory hypotheses are currently used (Dott [8] and Dott [9]): (i) on the one hand, some authors assume that sedimentary rocks are the result of a continuous and homogenous process through time; (ii) on the other hand, others maintain that only a few events, exceptional in intensity and duration, have a significant impact on the formation and preservation of sedimentary deposits (Bourrouilh-Le Jan et al [5]). 
The second hypothesis is based on the assumption that the preserved heterogeneities in observed reservoirs are mainly the result of the succession of fair-weather periods and high-energy exceptional events, i.e. low frequency storms (one every hundred years or more) and/or fluvial floods, characterized by a great intensity or sediment supply. Our numerical model is based on this assumption and therefore focuses mainly on a process-based modelling of exceptional events. Consequently, since the number of events to simulate is smaller, the simulation results can be obtained over much longer time periods.

\section{Detailed concepts}

\subsection{Summary of modelling sedimentary processes during storms}

Marine coastal environments are characterized by complex processes and their interaction. These processes differ by nature, spatial scale and duration. As a consequence, they do not affect sedimentary deposits in the same way. In the storm-dominated systems considered here, two types of currents are distinguished: oscillatory currents generated near the sea bottom by surface waves, and unidirectional currents such as littoral or downwelling currents. Both types of currents erode the sea bottom but the transport of suspension suspended particles is due mainly to unidirectional currents (Soulsby [19], Le Roux [13], Van Rijn [21]). The transport can be directed alongshore (littoral current generated by surface waves with an oblique direction with respect to the coast), offshore (downwelling current or storm current) or towards the shore (upwelling current or storm surge) (Grant and Madsen [10], Myrow and Southard [14], Hequette et al [11]). An example of a downwelling system is illustrated in Figure 1.

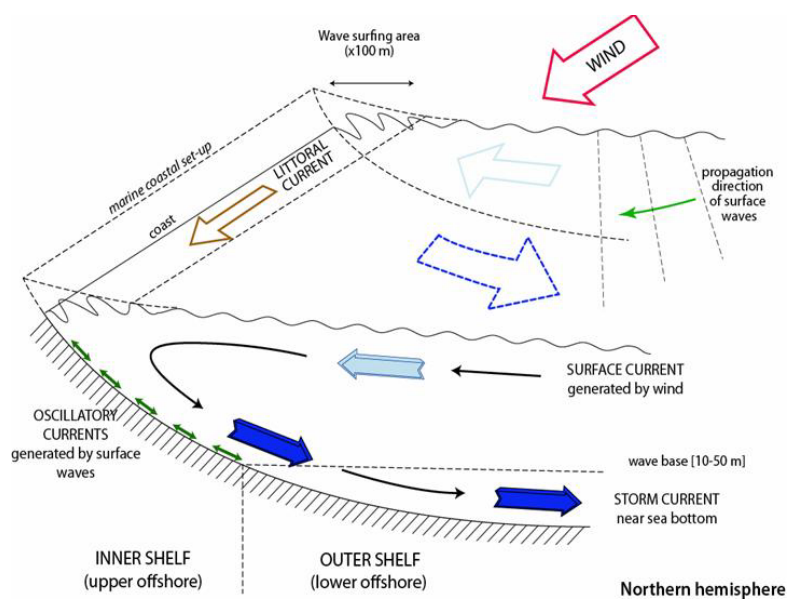

Figure 1: $\quad$ Physical processes during storm downwelling in a marine coastal environment. 


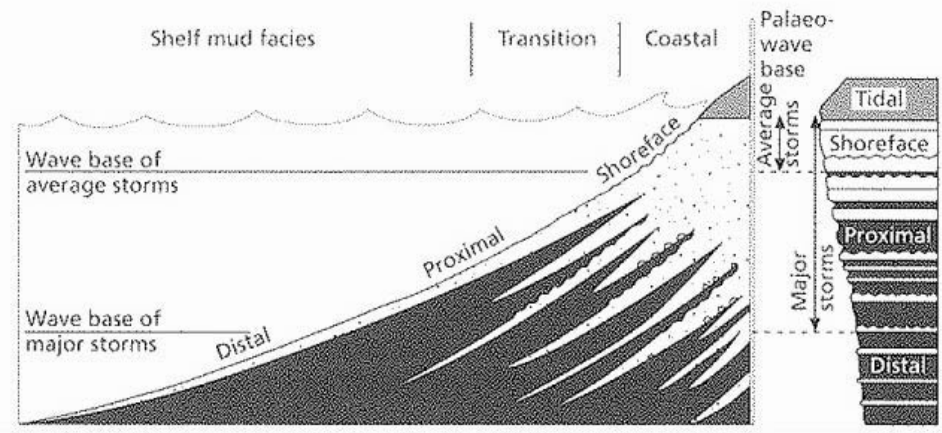

Figure 2: Idealized vertical facies sequence resulting from coastal progradation (modified from Aigner and Reineck [1]).

The resulting deposits in storm-dominated environments are composed of coarse storm beds (in dotted white on the schematic cross-section in Figure 2) alternating with finer beds formed during fair-weather periods (in black, Figure 2): these facies changes are responsible for heterogeneities in petrophysical properties and have a major impact on fluid flow in sedimentary reservoirs. Their rigorous modelling is thus of primary importance.

\subsection{Details of the numerical model}

\subsubsection{The modelling of storm periods}

The numerical modelling of storm periods is composed of two mutually interactive modules: a transport module, that computes sediment transport over the domain according to a velocity field, and a sedimentary module that computes current interactions with the sea bottom through the modelling of deposition and/or erosion processes.

\subsubsection{The transport module}

The velocity fields of downwelling and littoral currents are averaged on their water column height. They are computed over the whole domain and the empirical velocity formulation is deduced from energetic concepts. A simple approach was chosen in this model (i) in order to avoid the use of a full hydrodynamic model and (ii) for computational time reasons. However it is possible to couple the model with any hydrodynamic code providing velocity fields of littoral and downwelling currents, or to improve the current solution since more complex velocity formulations are known and could be implemented.

Littoral currents are generated by the energy losses of oblique waves when they surf near the shore. The selected formulation for the velocity $V_{\text {littoral }}$ is expressed as follows (Thornton and Guza [20]) where velocity is function of wave energy density flux directed towards shoreline $\left(E_{w} \cdot C_{g}\right.$, based only on wave characteristics) and incidence angle of waves on shoreline $\theta$ : 


$$
V_{\text {littoral }}=-\frac{\pi C}{\rho f_{w} g H} \frac{\partial\left(E_{w} C_{g} \cos \theta\right)}{\partial x} \frac{\sin \theta_{0}}{C_{0}}
$$

During storm events, a surface current is originated by the wind and supplies to the shoreline sea water that generates a coastal surge (also called coastal setup). We assume that this surge is the main cause of the downwelling currents, and their velocities are function of the local setup. All unidirectional current velocities are then combined at each cell location: the resulting velocity field represents the transport of suspended sediments over the simulation domain. Other types of currents can be added, density current for instance or storm washover.

The time steps, computed at each iteration from the velocity field, range from several seconds to several minutes during storm periods.

\subsubsection{The sedimentary module}

The sedimentary module takes into account several lithologies characterized by their sediment granulometry and by their density. The total shear-stress $\tau$ is defined as the non-linear combination of unidirectional shear stress (computed from Jonsson [12]) and oscillatory current shear stress (computed from Soulsby [19]) which depends on the angle between these two different currents. For each lithology, the total shear stress is compared to the shear-stress threshold for this lithology $\tau_{\text {cri }}$ (Soulsby [19]). The excess shear stress is then used to compute erosion or deposition rate.

Erosion occurs when the total shear-stress exceeds the critical shear stress. The erosion rate $E_{i}$ is the product of the shear-stress excess and an empirical erosion factor M (Partheniades [17]):

$$
E_{i}=M \cdot \frac{\tau-\tau_{c r, i}}{\tau_{c r, i}}
$$

On the contrary, if the total shear-stress is lower than the critical shear-stress, deposition of suspended sediments occurs. The deposition rate $\mathrm{D}_{\mathrm{i}}$ is function of the settling velocity $\mathrm{v}_{\mathrm{si}}$, of the near-bed concentration $\mathrm{C}_{\mathrm{bi}}$ and of the shear-stress (Smith and Mc Lean [18]):

$$
D_{i}=v_{s i} \cdot C_{b i} \cdot \frac{\tau_{c r, i}-\tau}{\tau_{c r, i}}
$$

\subsubsection{The modelling of fair-weather periods}

Fair-weather periods are currently simulated through two ways: (i) a mean aggradation of fine sediments under the wave action limit which represents decantation in deep marine domain, and (ii) a mean aggradation of coarse sediments in the shoreface which simulates input of sediment through the littoral drift. The time steps during fair-weather periods are fixed by the user: it ranges from several years to a hundred years, according to the storm frequency. 


\section{First results}

\subsection{Synthetic test of the model}

The numerical model was applied first to a synthetic case. The example presented below is a uniformly inclined bathymetry (slope of $0.17^{\circ}$ ). The simulation domain is $32 \mathrm{~km}$ long (from onshore to offshore) and $24 \mathrm{~km}$ wide (along the coast). Each cell is $200 \mathrm{~m} \times 200 \mathrm{~m}$.

The simulated storm is moderate (wind velocity of $70 \mathrm{~km} / \mathrm{h}$ ). It lasts $27 \mathrm{~h}$ with an increasing intensity in the first phase $(6 \mathrm{~h})$, a stable phase of $6 \mathrm{~h}$ at maximum intensity and a relaxation phase of $15 \mathrm{~h}$. The maximum values of wave height and period are respectively about $5 \mathrm{~m}$ and $12 \mathrm{~s}$. These simulation conditions are representative of classical winter storms on the US west coast, and modelled currents are realistic in comparison with actual measurements (Figure 3) (Cacchione et al [6], Ogston and Sternberg [15], Wright et al [22]). In addition, the wind blows towards the coast and a coastal set-up is modelled generating a downwelling current. The wave trains are defined parallel to the coast so that no littoral current is generated.
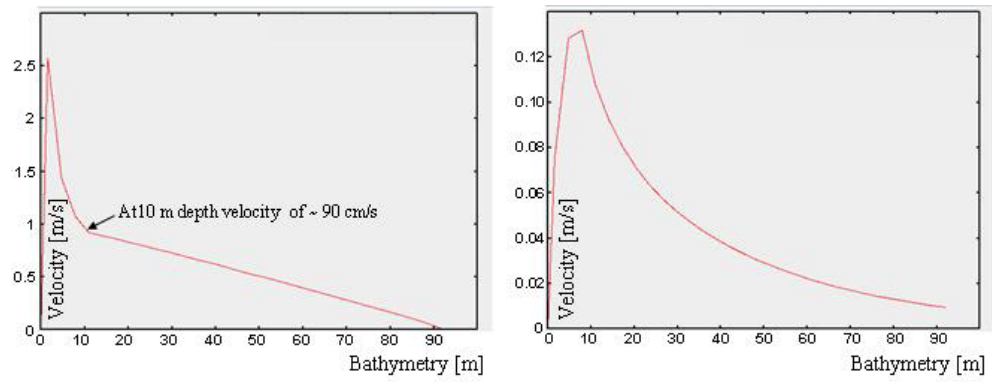

Figure 3: Evolution from shore to offshore (in cross section) of downwelling current velocity (on the left) and of oscillatory current velocity (on the right).

As expected, the more energetic the environment, i.e. when the interaction between wave-induced oscillatory currents and downwelling current is maximised, the stronger the sediment erosion. As a consequence, modelling results show (i) sea bottom erosion near the shoreface, where the conditions are the most energetic at the beginning of the simulation, (ii) suspended sediment transport towards the offshore and, (iii) deposition in the deeper domain where the energy of the environment decreases. The model shows a total erosion thickness (cumulative value) of $3 \mathrm{~mm}$ for bathymetry values lower than $20 \mathrm{~m}$, whereas deposits (less than $1 \mathrm{~mm}$ thick) are simulated in the deeper domain (bathymetries deeper than $20 \mathrm{~m}$ ) (Figure 4). These orders of magnitude are consistent with observations made on the California shelf (Cacchione et al [6], Ogston and Sternberg [15], Wright et al [22]). 


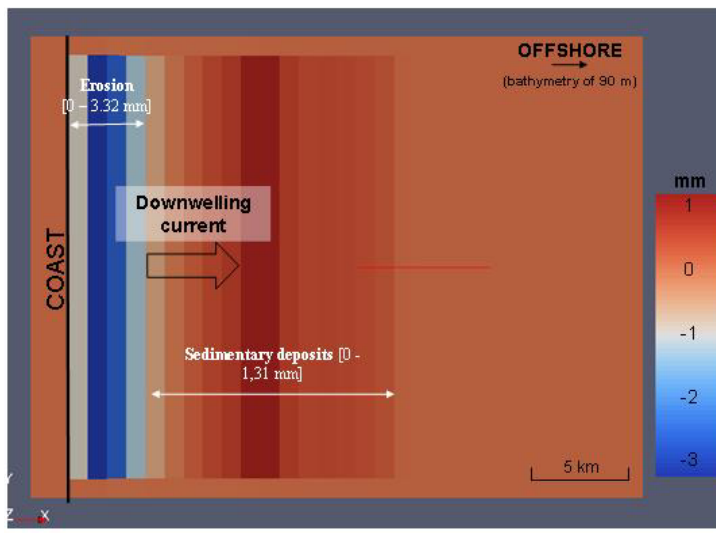

Figure 4: Elevation difference (at the end of the modelling lasting $27 \mathrm{~h}$ ) compared to the initial topography.

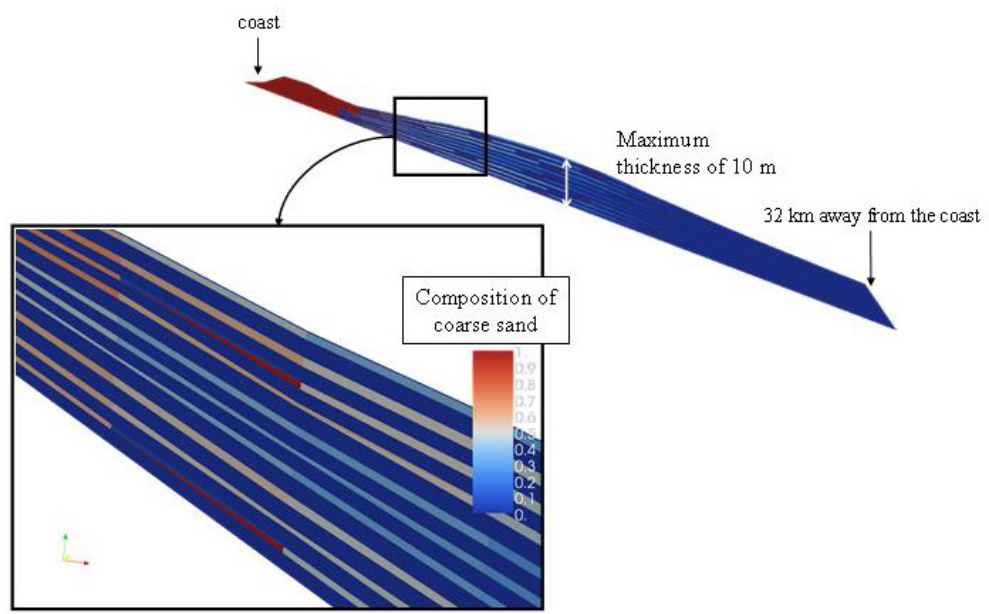

Figure 5: Cross-section through the 3-D model illustrating the modelled sequence of sedimentary deposits. Simulated time: 1000 years, Environment: shallow marine clastic. Event: moderate storms (1 per 100 years). Vertical exaggeration factor: 250 .

In order to simulate deposits within a time frame representative of the formation of real sedimentary reservoir bodies, a series of storms strongest than to the one presented above were simulated. The frequency of storms is one per hundred years. Between the storms, continuous sedimentation is simulated by pure aggradation. Figure 5 shows a cross-section of the result highlighting the stack of storm deposits. Grain size-dependent sorting of deposits is well reproduced. 


\subsection{Application to a case study: present-day storms in the Gulf of Lions (France)}

A model validation was performed on a modern environment in the Gulf of Lions (South of France) (Figure 6). The modelled area has been chosen where downwelling currents take place, and away from the fluvial current at the Rhone mouth and from the cascading currents present in the South of the shelf. Preliminary results are presented here below.
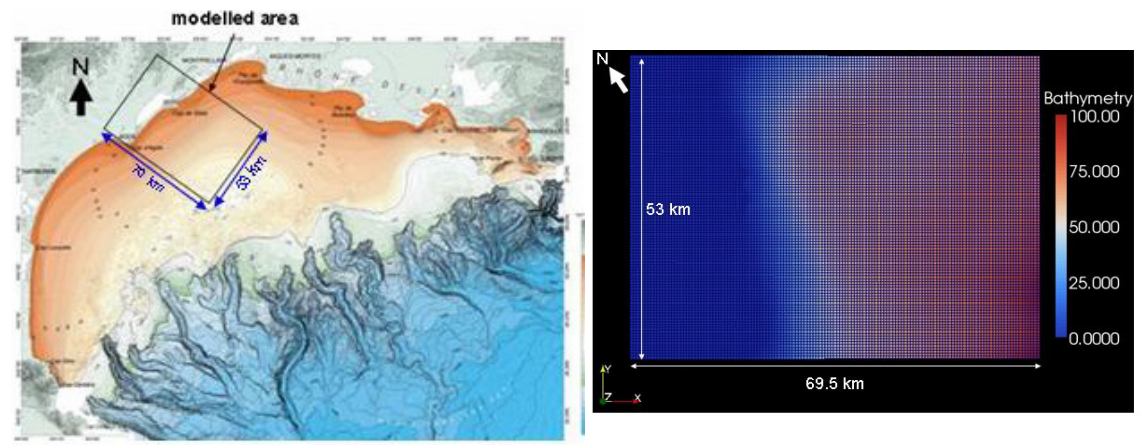

Figure 6: On the left: Morphobathymetric map of the Gulf of Lions (France) (modified from Berné and Gorini [3]). On the right: Initial bathymetry map used in the numerical modelling.

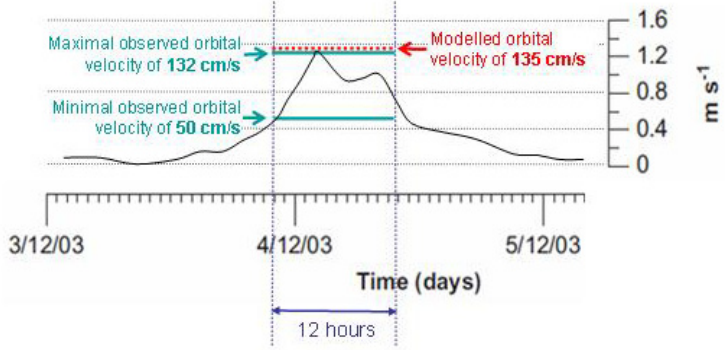

Figure 7: Evolution through time of observed orbital velocity at $28 \mathrm{~m}$ depth (near the sea bottom) during a 50 years-recurrence storm (December $12^{\text {th }}, 2003$ ) (modified from Palanques et al. [16]). The 12 hours time range corresponds to the duration of the modelled storm.

The simulated storm is representative of classical storms that are observed on average every fifty years (Bourrin et al. [4], Palanques et al. [16]). Its main characteristics are the following: average wind velocity of $108 \mathrm{~km} / \mathrm{h}$ perpendicular to the shoreline, surface waves defined by a period of $10 \mathrm{~s}$ and a height of $7.5 \mathrm{~m}$ coming from East. The modelled wave-induced oscillatory currents are in the range of observed velocities at $28 \mathrm{~m}$ (Figure 7). 
For this simulation, the wind has generated a maximal coastal set-up of $51 \mathrm{~cm}$ and a return current, offshore-directed, with velocity values spatially ranging from 8 to $64 \mathrm{~cm} / \mathrm{s}$. It combines near the shore with the wave-induced littoral current (velocity values spatially ranging from 1 to $210 \mathrm{~cm} / \mathrm{s}$ ) in a resulting unidirectional current consistent with observations: it gives a value of $34 \mathrm{~cm} / \mathrm{s}$ at $28 \mathrm{~m}$ (Figure 8).

The modelled total (wave- and current-induced) shear-stresses range from 0.1 to $23.3 \mathrm{~N} / \mathrm{m}^{2}$ and give a value at $28 \mathrm{~m}$ of $4 \mathrm{~N} / \mathrm{m}^{2}$ which is consistent with observations (Figure 9)

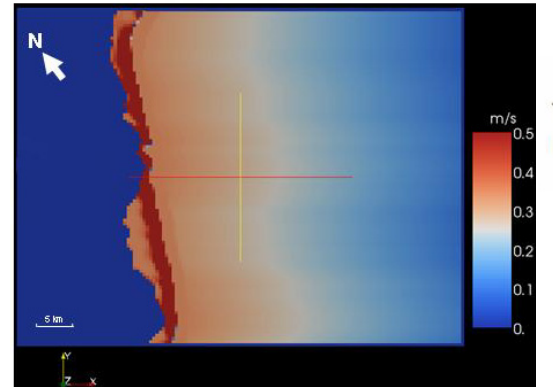

(a)

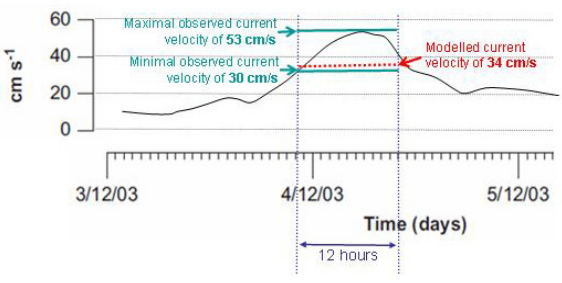

(b)

Figure 8: (a) Modelled velocities of unidirectional current resulting from combination of littoral and return currents. (b) Evolution through time of observed current velocity at $28 \mathrm{~m}$ depth (near the sea bottom) during a 50 years-recurrence storm (December $12^{\text {th }}, 2003$ ) (modified from Palanques et al. [16]). 12 hours time range corresponds to the duration of the modelled storm.

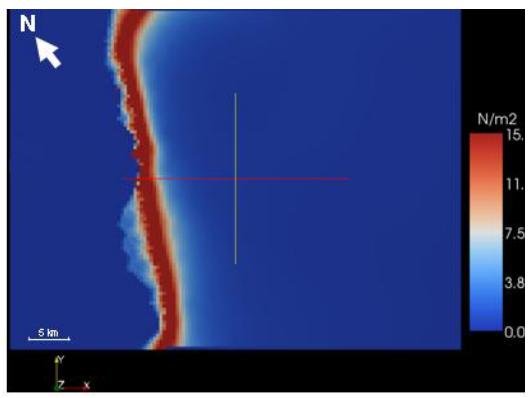

(a)

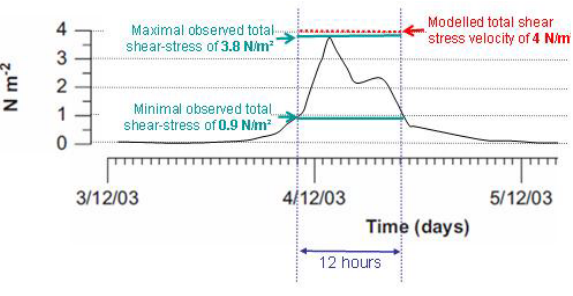

(b)

Figure 9: (a) Modelled total shear-stresses resulting from the combination of unidirectional and oscillatory currents. (b) Evolution through time of observed total shear-stress at $28 \mathrm{~m}$ depth (near the sea bottom) during a 50 years-recurrence storm (December $12^{\text {th }}, 2003$ ) (modified from Palanques et al. [16]). 12 hours time range corresponds to the duration of the modelled storm. 
These preliminary results on hydrodynamic processes modelling are consistent with observations available on the Gulf of Lions (Palanques et al. [16], Bourrin et al. [4]) even if more work must be done on the calibration of the wind-induced coastal set-up that controls the return current velocity.

\section{Conclusions}

Many reservoir rocks are made of coastal deposits and the modelling of petrophysical properties, controlled by facies distribution, is a key to the understanding of fluid migration pathways at the recovery stage. In this context, a new 3-D numerical model designed to simulate deposit formation over tens to hundreds of thousands of years was developed. It aims at modelling in a deterministic manner the erosion, transport and deposition of sediments in clastic-dominated coastal environments.

Based on the hypothesis that the preserved sediments are mainly the results of high-energy low-frequency events, it combines a transport module and an erosion/deposition module that are coupled to obtain sedimentation and erosion rates and to respect the mass balance. The transport module focuses on the modelling of a velocity field resulting from the interaction of different unidirectional currents (downwelling and littoral currents) and the resulting transport of sediments. The approach is flexible, it proposes a simple approximation for the modelling of these velocities, but it could also accept velocity fields computed by a different code. The erosion/deposition module solves the sedimentation rate problem by computing the total shear-stress at the sea bottom.

A synthetic case illustrating the main features of the model in a simplistic environment is presented. First results of its application to a realistic case study in the Gulf of Lions are also shown. The simulated wave-induced orbital and unidirectional current velocities and resulting bed shear-stress are consistent with observations. This deterministic approach and its original implementation give encouraging prospects for helping to assign facies properties to subsurface geological grids.

\section{Acknowledgements}

We would like to acknowledge Grégoire Piquet for the tests he performed on the numerical prototype, Vanessa Teles for our collaboration on the computing developments and Didier Granjeon for his helpful comments on an earlier version of the manuscript.

\section{References}

[1] Aigner, T. \& Reineck, H. E., Proximality trends in modern storm sands from the Helegoland Bight (North Sea) and their implications for basin analysis. Senckenbergiana Marit., 14, pp. 183-215, 1982.

[2] Airy, G.B., Tides and waves. Encyc. Metrop., 192, pp. 241-396, 1845. 
[3] Berné, S. \& Gorini, C., The Gulf of Lions: An overview of recent studies within the French 'Margins' Programme. Marine and Petroleum Geology, 22(6-7), pp. 691-693, 2005.

[4] Bourrin, F., Monaco, A., Aloïsi, J.-C., Sanchez-Cabeza, J.-A., Lofi, J., Heussner, S., Durrieu de Madron, X., Jeanty, G., Buscail, R. \& Saragni, G., Last millennia sedimentary record on a micro-tidal, low-accumulation prodelta (Têt NW Mediterranean). Marine Geology, 243, pp. 77-96, 2007.

[5] Bourrouilh-Le Jan, F. G., Beck, C. \& Gorsline, D. S., Catastrophic events (hurricanes, tsunami and others) and their sedimentary records: Introductory notes and new concepts for shallow water deposits. Sedimentary Geology 199[1], pp. 1-11, 2007.

[6] Cacchione, D., Wiberg, P., Lynch, J., Irish, J. \& Traykovski, P., Estimated suspended-sediment fluxe and bedform activity on the inner portion of the Eel continental shelf, Marine Geology, 154, pp. 83-97, 1999.

[7] Dean, R.G. \& Dalrymple, R.A., Coastal Processes with Engineering Applications, Cambridge University Press, pp. 80-84.

[8] Dott, R. H., Episodic sedimentation - how normal is average? How rare is rare? Does it matter?, Journal of Sedimentary Petrology, 53, pp. 5-23, 1983.

[9] Dott, R. H., Episodic event deposits versus stratigraphic sequences - Shall the twain never meet? Sedimentary Geology, 104, pp. 243-247, 1996.

[10] Grant, W. D. \& Madsen, O. S., The continental-shelf bottom boundary layer. Annual Review of Fluid Mechanics, 18, pp. 265-305, 1986.

[11] Hequette, A., Desrosiers, M., Hill, P. R. \& Forbes, D. L., The influence of coastal morphology on shoreface sediment transport under storm-combined flows, Canadian Beaufort Sea. Journal of Coastal Research, 17(3), pp. 507516, 2001.

[12] Jonsson, I.G., Wave Boundary layers and friction factors. In: Proceedings of the $10^{\text {th }}$ International Conference on Coastal Engineering. American Society of Civil Engineers, Tokyo, pp. 127-148, 1966.

[13] Le Roux, J. P., Grains in motion: a review. Sedimentary Geology, 178, pp. 285-313, 2005.

[14] Myrow, P. M. \& Southard, J. B., Tempestite deposition. Journal of Sedimentary Research, 66(5), pp. 875-887,1996.

[15] Ogston, A. \& Sternberg, R., Sediment transport events on the northern California shelf. Marine Geology, 154, pp. 69-82, 1999.

[16] Palanques, A., Guillén, J., Puig, P. \& Durrieu de Madron, X., Storm-driven shelf-to-canyon suspended sediment transport at the southwestern Gulf of Lions. Continental Shelf Research, 28, pp. 1947-1956, 2008.

[17] Partheniades, E., Erosion and deposition of cohesive soils. Journal of the Hydraulic Division, 91, pp. 105-139; 1965

[18] Smith, J. D. \& McLean, S. R., Spatially averaged flow over a wavy surface. Journal of Geophysical Research, 82(12), pp. 1735-1746, 1977.

[19] Soulsby, R. L., Dynamics of Marine Sands. Thomas Telford Publications, London, UK, 249 pp., 1997. 
182 Island Sustainability

[20] Thornton, E. B. \& Guza, R. T., Surf zone longshore currents and random waves : field data and models. Journal of Physical Oceanography, 16(7), pp.165-178,1986.

[21] Van Rijn, L. C., Unified view of sediment transport by currents and waves. II: Suspended Transport. Journal of Hydraulic Engineering, 133(6), pp. 668-689, 2007.

[22] Wright, L., Kim, S. \& Friedrichs, C., Across shelf variations in bed roughness, bed stress and sediment suspension on the northern California shelf. Marine Geology, 154, pp. 99-115, 1999. 